\title{
Proposta de uma Biblioteca Digital para Trabalhos Monográficos
}

\author{
Celeste Magela Campos da Silva Guilherme Tavares de Assis \\ Centro Universitário de Belo Horizonte (Uni-BH)
}

\begin{abstract}
Resumo - Este artigo apresenta a proposta de uma biblioteca digital para organizar adequadamente os trabalhos monográficos vinculados a cursos de Instituições de Ensino Superior. Tal biblioteca digital visa o armazenamento de trabalhos produzidos por alunos, facilitando a pesquisa pela comunidade acadêmica. Para comprovar a eficácia e a eficiência da biblioteca proposta, um protótipo foi construído e experimentos práticos foram realizados por usuários reais, no intuito de se verificar a precisão quanto aos aspectos de usabilidade, aos requisitos de interface e à qualidade dos resultados obtidos.

palavras-chave - bibliotecas digitais, metadados, dublin core.
\end{abstract}

Abstract - This paper proposes a digital library to organize properly the course monographs of graduate schools. Such a proposed digital library aims the monographs storage generated by students, improving the research by the academic community. In order to demonstrate the effectiveness and the efficiency of the proposed digital library, a prototype was built and practical experiments were performed by real users, to analyze the accuracy on the issues of usability, requirements for interface and quality of the obtained results.

keywords - digital library, metadata, dublin core.

\section{INTRODUÇÃO}

Com o surgimento da Internet, foi possível reduzir grandes obstáculos tecnológicos quanto à disponibilização de documentos eletrônicos, permitindo o acesso à informação, independente de sua localização. Porém, essas informações encontram-se espalhadas pela $W e b$, existindo a necessidade de organizá-las. As Bibliotecas Digitais (BDs) surgiram como um forma de se obter essa organização, auxiliando a recuperação da informação desejada pelo usuário.
BDs, segundo a Digital Library Federation ${ }^{l}$, são sistemas eletrônicos de armazenamento de informações com capacidade para selecionar, estruturar, oferecer acesso intelectual, interpretar, distribuir, preservar a integridade e garantir a persistência, ao longo do tempo, das coleções de trabalhos digitais, para que estejam legíveis e disponíveis para uso por uma comunidade ou um conjunto de comunidades definidas. O conteúdo das BDs inclui metadados, podendo ser internos ou externos à biblioteca. Esses metadados são atributos de dados ou documentos, normalmente descritivos (como, por exemplo, informações sobre autor e conteúdo de uma publicação), freqüentemente subdivididos em categorias e registrados de acordo com algum padrão.

Os cursos de Pós-Graduação e grande parte dos cursos de Graduação de uma Instituição de Ensino Superior (IES) estabelecem que, ao final do curso, seus alunos apresentem um trabalho monográfico referente à área de sua formação, a fim de consolidar os conhecimentos adquiridos no curso. Porém, muitas vezes esses trabalhos não estão organizados digitalmente de maneira a facilitar o acesso aos mesmos pela comunidade acadêmica. Uma BD é uma ótima opção para resolução desse problema, já que oferece uma forma de preservação e armazenamento de documentos, trazendo agilidade na obtenção das informações.

Assim, o objetivo desse artigo é apresentar uma proposta de $\mathrm{BD}$, a fim de organizar

\footnotetext{
${ }^{1}$ Consórcio de bibliotecas e agências relacionadas que usa tecnologias de informação eletrônica para estender suas coleções e serviços.
} 
adequadamente os trabalhos monográficos desenvolvidos por alunos de IESs, facilitando a pesquisa e a disseminação de seus conteúdos científicos. Para comprovar a eficácia e a eficiência da biblioteca proposta, experimentos práticos foram realizados, envolvendo a construção de uma BD. A partir desse arquivamento, foi possível fazer várias operações de consulta envolvendo a biblioteca. Os experimentos foram feitos por usuários reais para verificar a precisão quanto aos aspectos de usabilidade, aos requisitos de interface e à qualidade das respostas pretendidas. Após a realização dos mesmos, foi feita uma análise dos resultados obtidos.

Este artigo encontra-se organizado da seguinte forma: na Seção 2, são descritos trabalhos relacionados à BDs; na Seção 3, é apresentada uma visão geral sobre BDs; na Seção 4, é descrita a proposta de uma BD para trabalhos monográficos; na Seção 5, são descritos os experimentos práticos realizados e os resultados obtidos; e, na Seção 6, são apresentadas as conclusões obtidas e as perspectivas de trabalho futuro.

\section{Trabalhos RELACiONADOS}

Considerando a grande importância das BDs no arquivamento e visibilidade de documentos científicos como artigos, teses e eventos, algumas IESs já utilizam de seus benefícios. Dentre as BDs existentes, pode-se citar: a Biblioteca Digital Brasileira de Computação (BDBComp $)^{2}$ criado pelo Departamento de ciência de computação da UFMG, e a Biblioteca Digital da Unicamp (SBU) ${ }^{3}$.

A BDBComp foi desenvolvida para resolver a necessidade de se criar mecanismos para arquivar, preservar e disseminar a riqueza de todo conhecimento científico produzido pela comunidade brasileira de computação. Ela apresenta atualmente 5504 entradas de artigos em periódicos brasileiros e em anais de eventos

\footnotetext{
${ }^{2}$ http://www.lbd.dcc.ufmg.br/bdbcomp/

${ }^{3}$ http://libdigi.unicamp.br/
}

realizados no Brasil. Além disso, conta com um serviço de auto-arquivamento para que pesquisadores, estudantes e profissionais possam submeter trabalhos científicos em seu repositório.

Já a SBU foi oficialmente instituída em novembro de 2001, com o objetivo de divulgar a produção científica/acadêmica da instituição em formato eletrônico. A intenção foi disponibilizar artigos, fotografias, ilustrações, obras de arte, revistas, registros sonoros, teses, vídeos e outros documentos de interesse ao desenvolvimento científico, tecnológico e sócio-cultural para a comunidade nacional e internacional.

\section{VisÃo GeRAL SOBRE BiblioteCAS DigitaIS}

Com o advento da Internet e o surgimento de novas tecnologias de padrões abertos, surgiu a necessidade de se desenvolver mecanismos de divulgação de publicações científicas, melhorando as relações sociais, econômicas, culturais e políticas.

Através desse advento e da utilização de computadores, tornou-se possível criar uma representação digital para combinar informações de bibliotecas tradicionais e arquivos, e instituir BDs que são coleções organizadas de informações no formato digital.

Segundo [6], quem criou a primeira BD mundial foi um cientista americano chamado Michael Hawley ${ }^{4}$ que, já nos anos 90, conseguiu apresentar seus benefícios. Desde então, as BDs não pararam de crescer e vem provocando uma grande transformação no mundo das publicações. É possível perceber o interesse não somente da comunidade de tecnologia, mas também das compostas por bibliotecários.

BDs surgiram como uma solução a fim de facilitar o processo de armazenamento e divulgação de publicações, com o objetivo de disponibilizar materiais e serviços e atender prontamente às necessidades de seus usuários,

\footnotetext{
${ }^{4}$ Michael é professor do Media Lab, laboratório de meios de comunicação do Instituto de Tecnologia de Massachusetts (MIT), nos EUA.
} 
além de oferecer uma forma alternativa de preservação e armazenamento dos mesmos.

A interoperabilidade é um conceito chave que tem sido aplicado na utilização de BDs, pois é o grande facilitador na utilização dos padrões abertos. Esta interoperabilidade envolve um conjunto de metadados e outros aspectos, como tipo de arquitetura, permitindo grande abertura para criação de serviços de terceiros, além de utilizar mecanismos de integração com outras BDs. Mas a obtenção de interoperabilidade não é uma tarefa tão simples. É necessária a definição de um conjunto mínimo de metadados e uma concordância no uso de sintaxe comum em $\mathrm{XML}^{5}$ para representar e transportar os conjuntos de metadados de cada repositório.

Metadados, ou dados sobre outros dados (abstração dos dados), são muito importantes para obtenção de interoperabilidade. Segundo [3], metadados significam informações que descrevem o conteúdo dos registros dos repositórios que, por sua vez, são documentos eletrônicos (artigos, teses e outros). Alguns exemplos de metadados, referentes a uma publicação, são: título, autor, resumo, palavraschave.

Um registro de metadados consiste em um conjunto de atributos ou elementos necessários para descrever um recurso em questão. Por exemplo, em um sistema para uma biblioteca tradicional, o catálogo de metadados para esse sistema deverá conter um conjunto de registros com elementos que descrevem uma publicação dessa biblioteca: autor, título, data da criação e o número de chamada especificando o local da publicação na estante.

Para [2] é muito importante se propor e construir uma solução que possibilite a comunicação entre os vários repositórios sem que haja a necessidade de que tais repositórios sigam o mesmo padrão de representação de metadados. A solução proposta é a criação de um mecanismo que possibilite a manipulação de vários padrões de maneira que não seja

\footnotetext{
5 Extensible Markup Language (XML), linguagem de marcação de textos estendida.
}

necessário adequar as estruturas já existentes em cada repositório a um dado padrão, permitindo a melhor troca de dados entre repositórios e provendo maior qualidade de resposta às pesquisas.

Ainda, segundo [3] grandes quantidades dos dados da Web estavam espalhados, o que exigia um esforço para integrá-los e disseminá-los. Atualmente, utiliza-se um paradigma de representação em metadados criados por tecnólogos que buscavam descritores mais eficientes e dotados de uma tecnologia que permitisse o manuseio e gerenciamento de informação por máquinas com um mínimo de intervenção.

Portanto, existe um esforço muito grande no desenvolvimento, organização e padronização do uso de metadados. Desta forma, diferentes padrões foram criados, já que não existia uma forma única de representar os dados, e diferentes linguagens de representações eram usadas. Dentre esses padrões, pode-se citar o Dublin Core, mantido pela Dublin Core Metadata Initiative (DCMI). Além disso, os metadados devem seguir algum tipo de protocolo a fim de permitir a transferência e reunião de informações sobre documentos distribuídos em diversas partes da rede, proporcionando visibilidade e integração entre informações. Um exemplo de protocolo é o Open Archives Initiative (OAI). O padrão Dublin Core e o protocolo OAI serão discutidos nas subseções seguintes.

\subsection{DUBLIN CORE}

Dublin Core Metadata Element Set ou somente Dublin Core é a iniciativa para organização e padronização do uso de metadados, concebida em 1994 por Stuard Weisel, pesquisador da Online Computer Library Center (OCLC). Seu desenvolvimento ocorreu por meio de uma série de seminários que aconteceram a partir de 1995, tendo participação da comunidade bibliotecária e de pesquisadores de outras áreas de conhecimento. 
Dublin Core é usado para descrever documentos eletrônicos na Web, com o propósito de ser um meio de comunicação e de procura de informações. Este formato padronizado, de simples utilização, fornece recursos necessários para descrever, identificar, processar, localizar, recuperar e filtrar documentos digitais publicado em rede. Considera tais documentos como objetos e integra todos os possíveis tipos de materiais, sejam bases de dados, imagens, textos, vídeos e objetos multimídia.

Conforme demonstrado em [1], o Dublin Core é definido por meio de um conjunto de elementos de metadados planejado para facilitar a descrição de recursos eletrônicos ${ }^{6}$. Este conjunto de elementos pode ser dividido em dois níveis: simples e qualificado. O tipo simples compreende quinze elementos conforme apresentado na Tab. 1. Nela, está listado cada elemento, composto pela sua descrição e as diretrizes básicas para sua criação e utilização.

Tabela I

Elementos Dublin Core simples

\begin{tabular}{|l|l|}
\hline \multicolumn{1}{|c|}{ Elemento } & \multicolumn{2}{|c|}{ Descrição do Elemento } \\
\hline Title & $\begin{array}{l}\text { O nome dado ao recurso. } \\
\text { Tipicamente, título é um nome } \\
\text { dado pelo autor ou editor a um } \\
\text { trabalho. }\end{array}$ \\
\hline Creator & $\begin{array}{l}\text { Uma entidade principalmente } \\
\text { responsável por criar o } \\
\text { conteúdo do recurso. Uma } \\
\text { entidade pode ser uma pessoa, } \\
\text { uma organização, ou um } \\
\text { serviço. Tipicamente o nome } \\
\text { do criador deve ser usado para } \\
\text { indicar a entidade. }\end{array}$ \\
\hline Subject & $\begin{array}{l}\text { O tópico do conteúdo do } \\
\text { recurso. Tipicamente, um } \\
\text { assunto será expresso como } \\
\text { palavras-chave, frases-chaves, } \\
\text { selecionadas de } \\
\text { vocabulário controlado. }\end{array}$ \\
\hline
\end{tabular}

${ }^{6}$ Documentos ou publicações.

\begin{tabular}{|c|c|}
\hline Description & $\begin{array}{l}\text { Uma descrição do conteúdo do } \\
\text { recurso. Descrição pode } \\
\text { incluir um sumário, tabela de } \\
\text { conteúdo, livro-texto do } \\
\text { conteúdo ou resumo. }\end{array}$ \\
\hline Publisher & \begin{tabular}{|lrr}
\multicolumn{3}{|l}{ Entidade responsável por fazer } \\
o documento disponível. \\
Exemplos de & publicador \\
incluem & uma & pessoa, \\
organização ou & serviço. \\
Tipicamente o nome de um \\
publicador deveria ser usado \\
para indicar a entidade.
\end{tabular} \\
\hline Contributor & $\begin{array}{l}\text { Entidade responsável por fazer } \\
\text { contribuições ao conteúdo do } \\
\text { recurso. }\end{array}$ \\
\hline Date & $\begin{array}{l}\text { Data da criação ou } \\
\text { disponibilização do recurso. }\end{array}$ \\
\hline Type & \begin{tabular}{llr} 
A natureza & ou gênero & do \\
conteúdo do recurso. & Tipo \\
inclui & condições & que \\
descrevem & categorias & gerais, \\
funções, & gêneros & ou \\
agregações. & Existe & um \\
vocabulário padrão do & Dublin \\
\multicolumn{4}{l}{ Core para este elemento. }
\end{tabular} \\
\hline Format & $\begin{array}{l}\text { Manifestação física ou digital } \\
\text { do recurso. Tipicamente, } \\
\text { formato pode incluir o tipo de } \\
\text { mídia ou dimensão do recurso. } \\
\text { Usado para determinar o } \\
\text { hardware ou software ou outro } \\
\text { equipamento necessário para } \\
\text { exibir ou executar o recurso. }\end{array}$ \\
\hline Ident & $\begin{array}{l}\text { Identificador único do recurso } \\
\text { dentro de um dado contexto. } \\
\text { Exemplos de sistemas de } \\
\text { identificação incluem a URL } \\
\text { ou ISBN. }\end{array}$ \\
\hline Source & $\begin{array}{l}\text { Referência do qual o presente } \\
\text { recurso é derivado (fonte). }\end{array}$ \\
\hline Language & $\begin{array}{|lll|}\text { Linguagem } & \text { ou idioma } & \text { do } \\
\text { conteúdo } & \text { intelectual } & \text { do } \\
\text { recurso. } & & \\
\end{array}$ \\
\hline Relation & $\begin{array}{l}\text { Referência a um recurso } \\
\text { relacionado. }\end{array}$ \\
\hline
\end{tabular}




\begin{tabular}{|l|l|}
\hline Coverage & Extensão ou escopo do \\
conteúdo do recurso. Inclui \\
local de espaço tipicamente \\
(um nome de lugar ou \\
coordenadas geográficas), \\
período temporal ou \\
jurisdição. \\
\hline $\begin{array}{l}\text { Rights } \\
\text { Management }\end{array}$ & $\begin{array}{l}\text { Informações sobre os direitos } \\
\text { inerentes ao recurso: } \\
\text { informações sobre propriedade } \\
\text { intelectual, direitos autorais e } \\
\text { de propriedade. }\end{array}$ \\
\hline
\end{tabular}

Já o Dublin Core qualificado inclui três elementos adicionais, também chamados qualificadores, que refinam a semântica dos elementos de maneira que podem ser úteis na descoberta do recurso. Eles estão apresentados na Tab. 2.

Tabela II

Elementos Dublin Core qualificado

\begin{tabular}{|c|c|}
\hline Elemento & Descrição do Elemento \\
\hline Audience & $\begin{array}{l}\text { Uma classe de entidade para } \\
\text { quem o recurso é planejado ou } \\
\text { útil, podendo ser determinada } \\
\text { pelo criador ou publicador ou } \\
\text { por um terceiro. }\end{array}$ \\
\hline Provenance & $\begin{array}{l}\text { Declaração de qualquer } \\
\text { mudança em propriedade e } \\
\text { custódia do recurso, que é } \\
\text { significante para sua } \\
\text { autenticidade, integridade e } \\
\text { interpretação. A declaração } \\
\text { pode incluir uma descrição de } \\
\text { qualquer mudança que foi feita } \\
\text { no recurso. }\end{array}$ \\
\hline Rights Holder & 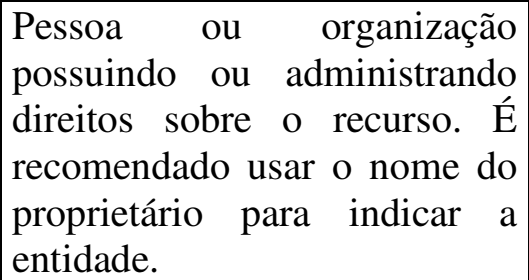 \\
\hline
\end{tabular}

A adoção em larga escala de padrões e de práticas descritivos para recursos eletrônicos melhora a recuperação dos mesmos. A associação desses metadados tem o potencial para melhorar a descoberta do recurso permitindo buscas baseadas em campos, por exemplo, autor, título, e permitindo a indexação de objetos e acesso ao índice.

Segundo [7], as principais características do padrão Dublin Core são:

a) simplicidade de criação e manutenção;

b) semântica geralmente compreendida;

c) escopo internacional;

d) extensibilidade.

A simplicidade é adquirida porque apresenta um conjunto de elementos pequeno e simples, permitindo que um não-especialista crie registros descritivos simples de forma fácil e barata.

Conforme identificado na alínea "b", o Dublin Core pode ajudar um pesquisador nãoespecialista a encontrar o que procura de maneira a apoiar um conjunto comum de elementos, pois apresenta uma semântica que é universalmente compreendida e suportada.

Já na alínea "c", o conjunto do elemento do Dublin Core foi desenvolvido originalmente em inglês, mas estão sendo criadas versões em outras línguas, incluindo finlandês, norueguês, tailandês, japonês, francês, português, alemão, grego, indonésio, e o espanhol, além de existir esforços para unir estas versões em um registro distribuído.

$\mathrm{Na}$ alínea "d", existe a necessidade de recuperação precisa dos recursos; por isso, os colaboradores do Dublin Core reconheceram a importância de fornecer um mecanismo para estender o conjunto desses elementos para necessidades descobertas adicionais do recurso.

Segundo [5], o cenário futuro mais imediato aponta uma direção da criação de métodos de organização dos dados de diferentes materiais das bibliotecas acessíveis online. Essas tendências sugerem uma mudança de paradigma em relação a classificação documental. Assim, a organização da informação apresenta uma 
inovadora arquitetura hipertextual ${ }^{7}$ e não linear proporcionando, também, uma mudança de paradigma na organização do conhecimento. Contudo, espera-se que novas propostas para aperfeiçoamento ou adoção de um formato como o Dublin Core aconteça em outros níveis institucionais biblioteconômicos de outros países.

\subsection{OAI}

Segundo [3], OAI teve suas raízes na comunidade E-Prints ${ }^{8}$ e surgiu no final de 1999. A OAI é uma organização não-governamental formada por pesquisadores, bibliotecários, e outros profissionais cujo objetivo é promover soluções para facilitar a interoperabilidade entre BDs, visando a disseminação eficiente de informação sobre a literatura científica.

A E-prints foi idealizada por Stevan Harnad, principal motivador do auto-arquivamento, que se interessa em facilitar a participação de interessados na disponibilização livre de literatura acadêmica. Nela, foi criado o software eprints, que permite facilmente a construção de repositórios, oferecendo uma interface de submissão, gerenciamento e download de documentos digitais, sendo totalmente compatível com a OAI.

A falta de padrões, para disponibilização de informações na Web, motivou a criação de tal iniciativa, pois, com sua utilização, torna-se possível proporcionar simplicidade e eficiência na pretensão de unificar as consultas a bases de dados científicas e acadêmicas.

Um sistema, para estar em conformidade com a iniciativa OAI, deve conter dados para compartilhamento. Com os recursos oferecidos pela iniciativa, é possível melhorar significativamente a precisão das consultas eletrônicas e reduzir o tempo de procura.

\footnotetext{
7 Técnica de armazenamento e apresentação da informação baseada num sistema de referências cruzadas que formam uma rede de associações que ligam texto, imagens, sons e ações.

${ }^{8} \mathrm{http}: / / \mathrm{www}$.eprints.org/
}

Conforme citado por [3], antes porém da OAI, o autor escrevia suas publicações e, em busca de reconhecimento, enviava-as para uma revisão e aguardava a publicação. Após a publicação, o documento normalmente era arquivado em uma biblioteca e, para acessá-lo, era necessário dirigir-se à biblioteca e localizá-lo. Com a nova tecnologia proporcionada pela OAI, o autor, imediatamente após a conclusão de seu documento, pode depositar o arquivo em um provedor de dados e o documento torna-se disponível quase imediatamente para revisão pela comunidade, em texto completo e de fácil consulta através dos provedores de serviço da OAI.

Tal autor cita, ainda, que os participantes da iniciativa podem ser divididos em Provedores de Dados (Data Providers - DP) e Provedores de Serviços (Service Providers - SP). Os DP mantêm repositórios de documentos digitais que implementam o protocolo OAI como forma de expor os metadados de seus documentos. Os SP oferecem buscas a metadados, pois coletam, organizam e disponibilizam estes a fim de agregar valor à Iniciativa.

Através da iniciativa OAI, foi criado o protocolo Open Archives Initiative Protocol for Metadata Harvesting (OAI-PMH), que se consolidou como padrão de interoperabilidade entre BDs. É considerado o protocolo que realiza a colheita de metadados, "que especifica como dois sistemas de computadores podem se comunicar através de um conjunto de registros estruturados e de maneira contínua" [3].

$\mathrm{O}$ que caracteriza essa colheita seria o fato de que, periodicamente, é feita uma busca aos repositórios cadastrados, por meio do envio de solicitações, coletando os metadados para exibição pelos SP. O protocolo OAI-PMH apresenta 6 verbos, utilizados para recuperar as informações, conforme mostrado na Tab. 3. 
Tabela III

Verbos do Protocolo OAI-PMH

\begin{tabular}{|c|c|}
\hline Verbo & Descrição \\
\hline Identify & $\begin{array}{l}\text { Utilizado para recuperar as } \\
\text { informações sobre o DP. A } \\
\text { resposta mínima esperada } \\
\text { consiste em: nome do DP, } \\
\text { endereço do repositório } \\
\text { (URL), versão do protocolo e } \\
\text { endereço eletrônico do } \\
\text { administrador do repositório. }\end{array}$ \\
\hline $\begin{array}{l}\text { ListMetadata- } \\
\text { Formats }\end{array}$ & $\begin{array}{l}\text { Recupera os formatos de } \\
\text { metadados disponíveis no } \\
\text { repositório. O formato padrão } \\
\text { é Dublin Core. }\end{array}$ \\
\hline GetRe & $\begin{array}{l}\text { Recupera um único registro do } \\
\text { repositório. } \\
\text { especificar o formato dos } \\
\text { metadados, cujo padrão é } \\
\text { Dublin Core, e o identificador } \\
\text { do registro (Identifier), que é } \\
\text { único na comunidade OAI. }\end{array}$ \\
\hline ListRecords & $\begin{array}{l}\text { Realiza a colheita dos } \\
\text { metadados do repositório. }\end{array}$ \\
\hline ListIdentifiers & $\begin{array}{l}\text { É uma versão abreviada do } \\
\text { verbo ListRecords, que retorna } \\
\text { apenas os cabeçalhos dos } \\
\text { registros. }\end{array}$ \\
\hline$L t$ & $\begin{array}{l}\text { Lista a } \\
\text { repositório. }\end{array}$ \\
\hline
\end{tabular}

Para [4], o OAI-PMH vem se consolidando cada vez mais e espera-se que, em breve, tornese parte da infra-estrutura básica das BDs.

\section{Proposta da Biblioteca Digital}

Como já mencionado, o objetivo desse artigo é apresentar uma proposta de BD, para organizar adequadamente os trabalhos monográficos desenvolvidos por alunos de IESs. O esquema conceitual para o repositório da BD proposta está apresentado no diagrama na Fig. 1. Este foi criado a partir das seguintes informações relevantes a serem armazenadas sobre um trabalho monográfico:

a) autores (creator);

b) título (title);

c) data de criação (date);

d) breve descrição (description);

e) pessoas que contribuíram para o desenvolvimento do trabalho monográfico (contributor); neste caso, os professores orientadores;

f) assunto definido por meio de palavras chaves (subject);

g) tipo do documento (type); neste caso, é texto;

h) URLs onde encontra-se armazenado o trabalho monográfico (identifier);

i) áreas relacionadas (relation);

j) entidade responsável pela publicação (publisher);

k) formato digital (format);

1) idioma usado (language).

De acordo com a Fig. 1, o esquema conceitual inclui uma entidade principal (Work) que representa os trabalhos monográficos. Este tipo de entidade possui, além da chave primária (Id_trabalho), um conjunto de atributos monovalorados e multivalorados mencionados anteriormente. Tal esquema foi desenvolvido de modo a atender ao formato de metadados do Dublin Core em XML e permitir uma futura integração com outras BDs, via OAI. A Fig. 2 ilustra um documento XML referente a um trabalho monográfico da área de computação de acordo com o esquema conceitual apresentado.

Alguns atributos de metatados do Dublin Core não foram incluídos por não se aplicarem à proposta. São eles:

a) Coverage: área geográfica que o trabalho monográfico engloba;

b) Source: outras fontes das quais o trabalho monográfico se deriva;

c) Rights: direitos ou outras propriedades intelectuais, especificando as condições através das quais o trabalho monográfico pode ou não ser usado. 


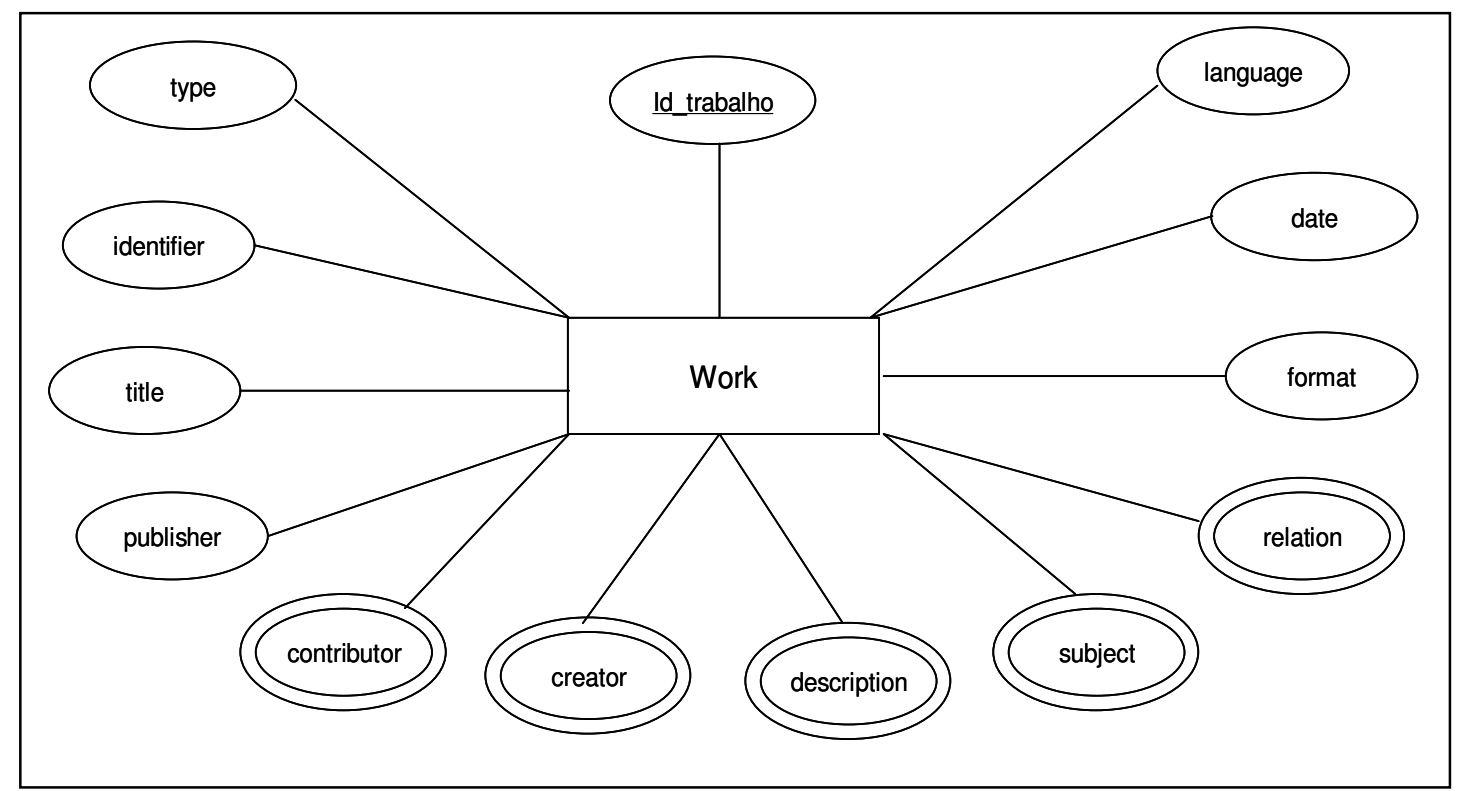

Figura 1 - Diagrama do esquema conceitual da BD proposta.

$<$ ?xml version="1.0" encoding="iso-8859-1" ?>

<rdf:RDF xmlns:rdf=http://www.w3.org/1999/02/22-rdf-syntax-ns\#

xmlns:dc="http://purl.org/dc/elements/1.1/">

$<$ rdf:Work>

$<$ dc:creator > Celeste Magela Campos da Silva</dc:creator>

$<\mathrm{dc}$ :title $>$ Construção de um protótipo para Biblioteca Digital de computação do

Uni-bh $</$ dc:title $>$

$<$ dc: date $>$ 2006-03-20</dc: date $>$

$<\mathrm{dc}$ :contributor $>$ Guilherme Tavares de Assis $</ \mathrm{dc}$ :contributor $>$

$<$ dc:subject $>$ Bibliotecas Digitais $</$ dc:subject $>$

$<$ dc:type $>$ text $</$ dc:type $>$

$<$ dc:identifier $>$ www.bdcuni.com.br/bdcuni.pdf $</$ dc:identifier $>$

$<$ dc: relation $>$ Recuperação de Informação $</$ dc: relation $>$

$<$ dc:publisher $>$ Uni-bh $</$ dc: publisher $>$

$<$ dc: format $>$ pdf $</$ dc: format $>$

$<\mathrm{dc}$ :language $>$ português $</ \mathrm{dc}$ :language $>$

$<\mathrm{dc}$ :description>Este trabalho tem como objetivo criar uma BD para organizar adequadamente os trabalhos monográficos desenvolvidos pelos alunos do curso de ciência da computação do UNI-BH </dc:description >

$</$ rdf:Work $>$

$</$ rdf:RDF $>$

Figura 2 - Exemplo de um documento XML conforme esquema conceitual. 


\section{EXPERIMENTOS PRÁTICOS}

Para avaliar a proposta sugerida de uma BD para trabalhos monográficos, foi desenvolvido um protótipo voltado para o armazenamento de trabalhos monográficos desenvolvidos no curso de Ciência da Computação do Centro Universitário de Belo Horizonte (Uni-BH), que se encontra na página http://www.cc.unibh.br/BDUNI2/. Tal protótipo foi denominado Biblioteca Digital de Computação do Uni-BH (BDCUni).

A interface da BDCUni foi criada utilizando a linguagem PHP. Já os dados foram armazenados no sistema de gerenciamento de bancos de dados relacional MySql, pelo fato de ser livre.

Para analisar tal protótipo, foi realizado um experimento que consistiu na aplicação de um questionário a 20 alunos da disciplina Algoritmos e Estruturas de Dados I (AEDS-I) do curso de Ciência da Computação. Tais participantes do experimento foram escolhidos, pois não possuem conhecimento sobre $\mathrm{BDs}$ e banco de dados, porém apresentam certa vivência com interfaces Web.

O questionário visou confrontar os detalhes quanto aos requisitos de interface, usabilidade e ergonomia do protótipo criado, apresentando 6 tarefas, onde cinco delas consistiram na realização de consultas na BDCUni, enfocando características distintas: pesquisa por autor, título, orientador, ano e área relacionada. A sexta tarefa foi uma consulta aleatória, ou seja, o participante escolheu os próprios parâmetros que desejava usar na consulta. Para tanto, o questionário relacionou perguntas a fim de analisar as observações levantadas quanto a navegação, telas e mensagens informativas e de erros. A BDCUni continha 51 trabalhos monográficos cadastrados de diferentes áreas de conhecimento da ciência da computação.

Analisando as respostas dos participantes no experimento realizado, pôde-se perceber que a $\mathrm{BD}$ proposta para $\mathrm{o}$ armazenamento $\mathrm{e}$ recuperação de trabalhos monográficos é bem eficiente e amigável. Mas também que algumas leves retificações precisariam ser feitas na interface da BDCUni, para melhorar ainda mais a iteração entre a aplicação e o usuário.

O restante desta Seção encontra-se organizada da seguinte forma: na Subseção 5.1, são apresentados os resultados quanto a navegação; na Subseção 5.2 são descritos os resultados quanto às telas; e na 5.3 , são apresentados os resultados quanto às mensagens.

\subsection{NAVEGAÇÃO}

Quanto à navegação, foi avaliado se as informações na tela estão organizadas de forma clara, e se a seqüência das telas percorridas para encontrar a informação desejada está coerente. Os resultados para as questões levantadas estão apresentados nas figuras Fig. 3, Fig. 4 e Fig. 5. As respostas foram consideradas levando em consideração níveis de 1 a 5 , sendo o nível 1 considerado como uma resposta ilógica ou confusa e o nível 5 considerada como uma resposta lógica ou clara.

Os gráficos apresentados nas figuras Fig. 3, Fig. 4 e Fig. 5 demonstram o nível de satisfação dos participantes quanto à navegação. Particularmente, a Fig. 3 ilustra a satisfação quanto a organização das informações nas telas, ficando $83 \%$ das respostas nos níveis 4 e 5, ou seja, a maioria dos participantes considerou ótima ou boa. O mesmo pode ser observado nas Fig. 4 e Fig. 5, onde o percentual nos níveis 4 e 5 foi de $94 \%$ e $88 \%$ respectivamente, demonstrando que a navegação foi considerada clara.

Além disso, algumas observações importantes foram levantadas, como por exemplo, (1) na tela de trabalhos recentes, não era apresentado quanto tempo estava sendo considerado como recente, o que dificultou o entendimento, porque a tela não trazia nenhum resultado (recentes são os trabalhos publicados nos últimos seis meses), (2) foi notada uma preocupação de se ter botões para agilizar o retorno às operações anteriores e, principalmente, para a tela principal, e (3) foi observado que as telas seguem o padrão do site 
do curso de Ciência da Computação do Uni-BH (http://www.cc.unibh.br).

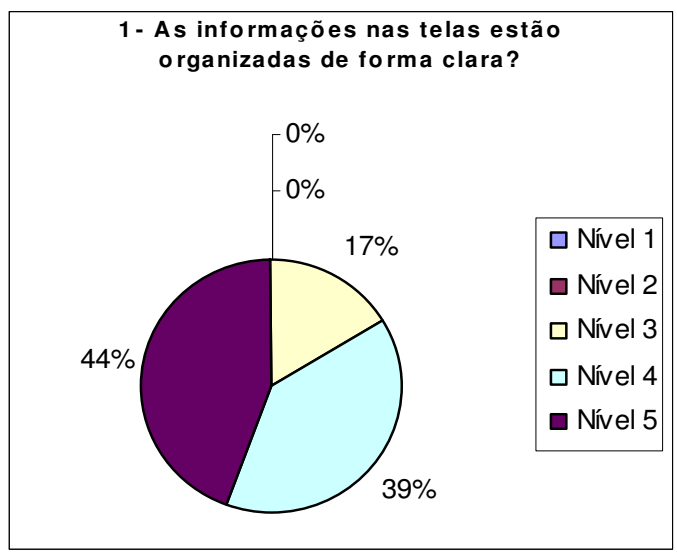

Figura 3 - Resultado da análise da pergunta 1.

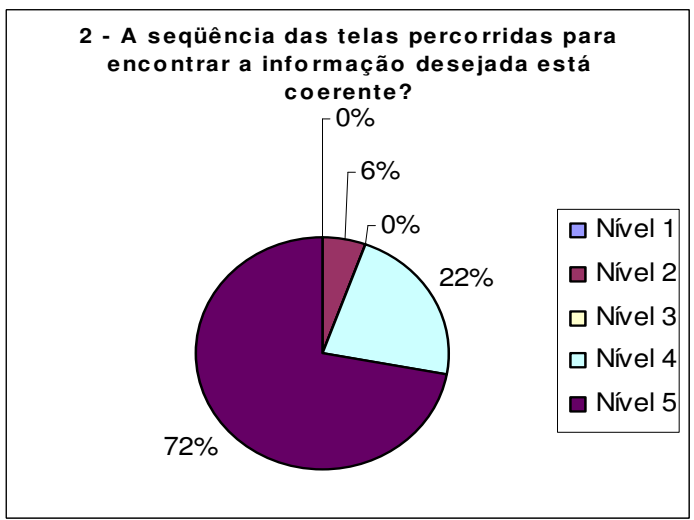

Figura 4 - Resultado da análise da pergunta 2.

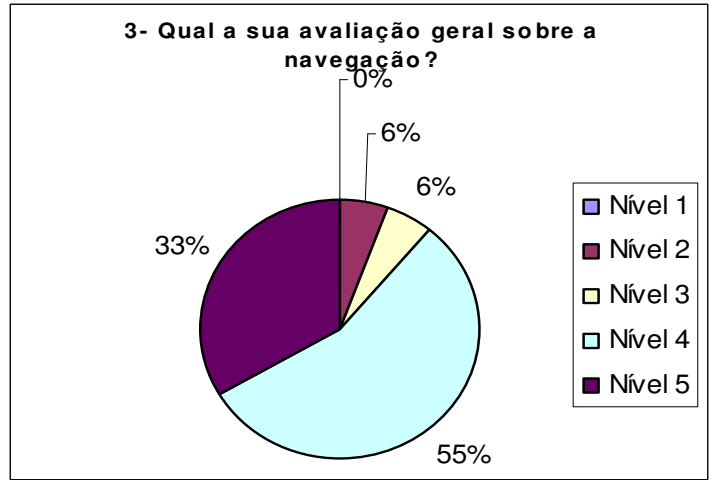

Figura 5 - Resultado da análise da pergunta 3.

De uma forma geral, todos os participantes consideraram a navegação simples, de modo que qualquer pessoa com conhecimento em Internet poderia utilizá-las, já que as telas facilitam a localização das operações de pesquisa pretendidas.

\subsection{TELAS}

Quanto às telas, foi avaliado se a manipulação e consulta às telas estão simples, e se os nomes dos botões estão coerentes com as suas funcionalidades. Os resultados para as questões levantadas estão representados nas figuras Fig. 6, Fig. 7, Fig. 8 e Fig. 9. As respostas foram consideradas levando em consideração níveis de 1 a 5, sendo o nível 1 considerado como uma resposta inadequada ou confusa e o nível 5 considerada como uma resposta adequada ou clara.

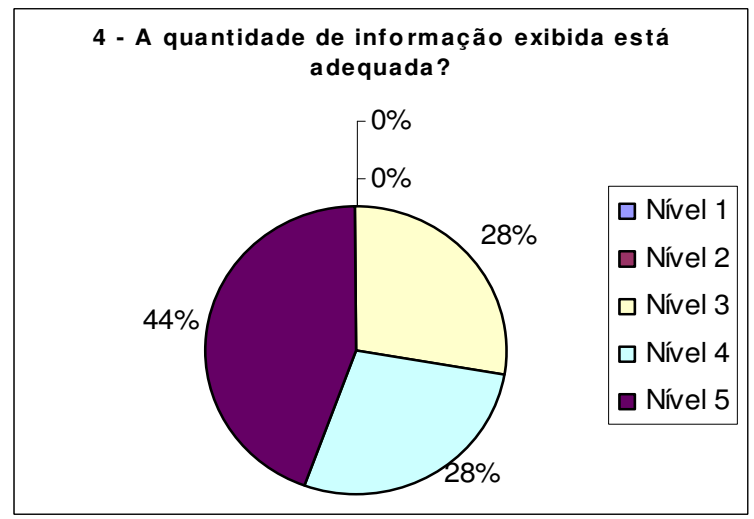

Figura 6 - Resultado da análise da pergunta 4.

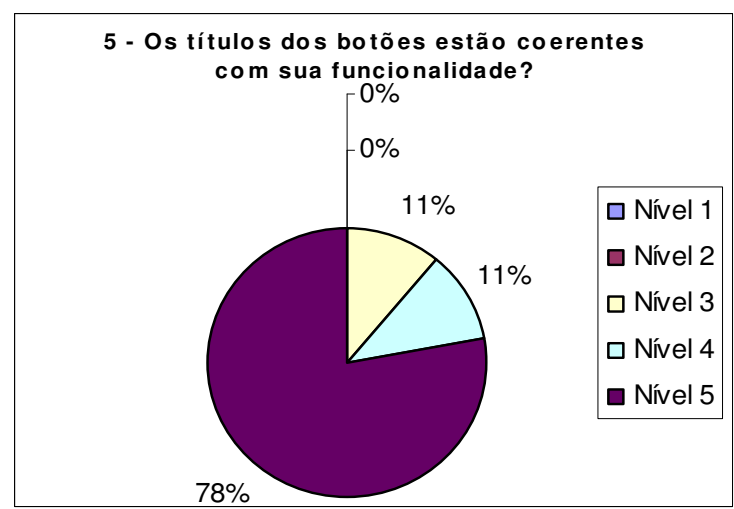

Figura 7 - Resultado da análise da pergunta 5. 


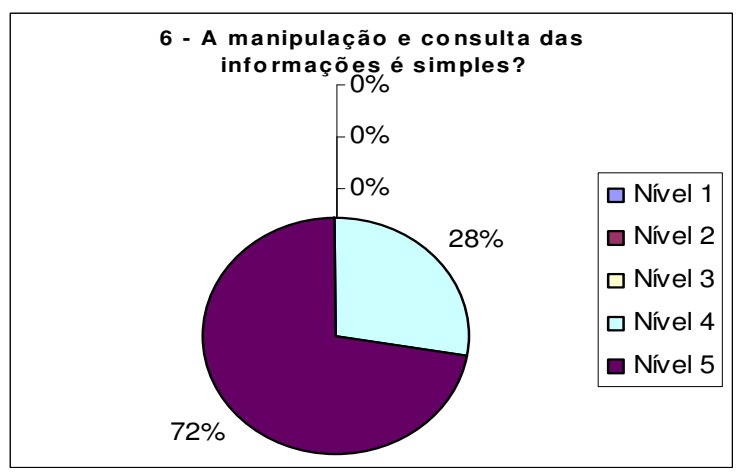

Figura 8 - Resultado da análise da pergunta 6.

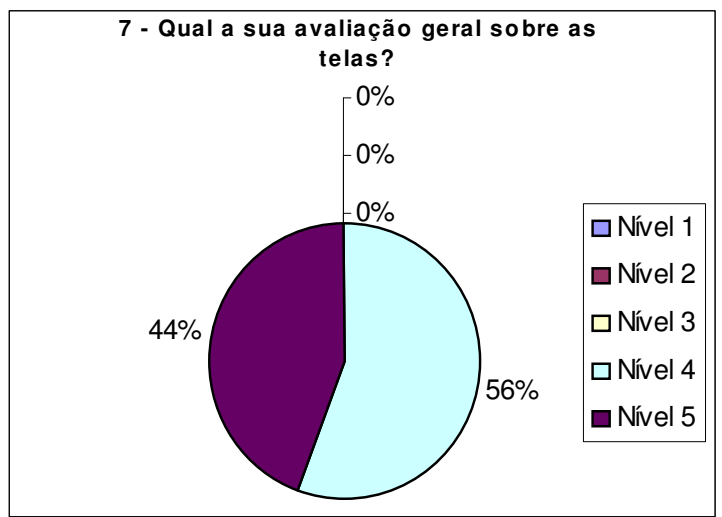

Figura 9 - Resultado da análise da pergunta 7.

Os gráficos apresentados nas figuras Fig. 6, Fig. 7, Fig. 8 e Fig. 9 demonstram o nível de satisfação dos participantes quanto às telas. A Fig. 6 ilustra a satisfação quanto à quantidade de informação exibida já que $72 \%$ dos participantes avaliaram a pergunta correspondente como adequada. $\mathrm{O}$ mesmo pode ser notado na Fig. 7, onde o percentual dos níveis 4 e 5 foi de $89 \%$. Já as figuras Fig. 8 e Fig. 9 demonstram que 100\% dos participantes escolheram apenas os níveis 4 e 5, indicando uma boa satisfação quanto às telas.

Uma observação importante levantada pelos participantes foi que, ao clicar no link para abrir o trabalho monográfico em PDF, este era exibido na mesma tela o que tornou difícil sua visualização. Este problema foi corrigido e o documento passou a ser visualizado em uma nova janela.
De uma forma geral, todos consideraram que as telas apresentam estruturas simples, claras e objetivas.

\subsection{MENSAGENS}

Quanto às mensagens, foi avaliado se as mensagens de orientação estão coerentes e se as mensagens de erros estão claras e adequadas. Os resultados para as questões levantadas estão representados nas figuras Fig. 10, Fig. 11 e Fig. 12. As respostas foram consideradas levando em consideração níveis de 1 a 5 , sendo o nível 1 considerado como uma resposta negativa ou confusa e o nível 5 considerado como uma resposta positiva ou clara.

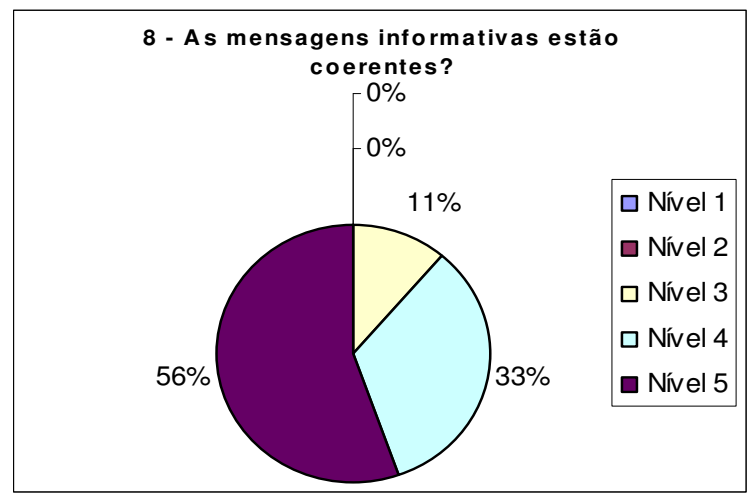

Figura 10 - Resultado da análise da pergunta 8.

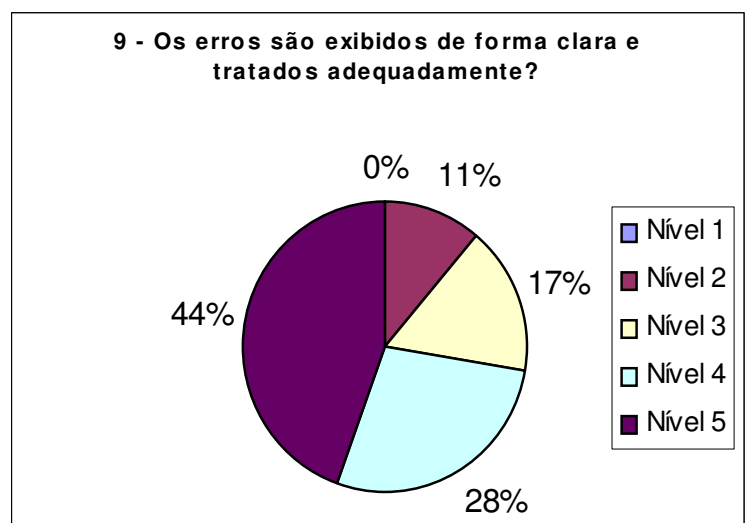

Figura 11 - Resultado da análise da pergunta 9. 


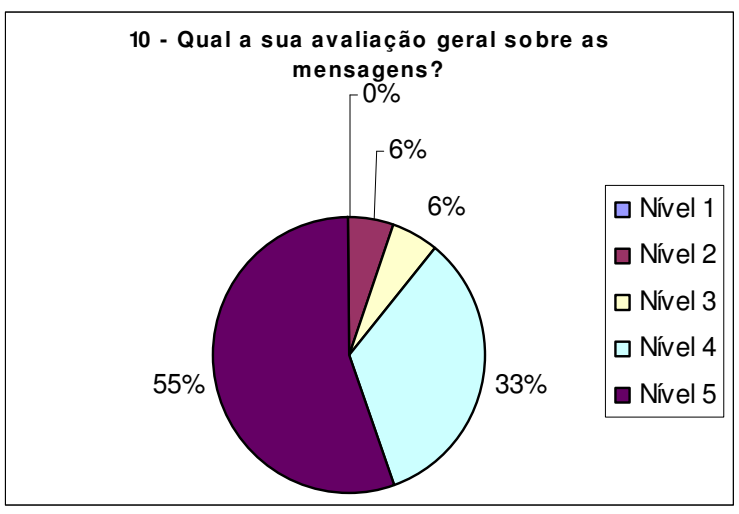

Figura 12 - Resultado da análise da pergunta 10

Os gráficos apresentados nas figuras Fig. 10, Fig. 11 e Fig. 12 demonstram o nível de satisfação dos participantes quanto às mensagens.

De uma forma geral, os participantes consideraram as mensagens simples, orientando claramente os mesmos sobre os possíveis problemas ocorridos. Isto pode ser observado nos gráficos das figuras Fig. 10 e Fig. 12, onde mais de $88 \%$ dos participantes consideraram as mensagens claras. Já a Fig. 11 apresenta um resultado aceitável, onde $72 \%$ dos participantes consideraram que as mensagens estão exibidas corretamente, enquanto que $28 \%$ consideraram uma apresentação razoável das mensagens. Este percentual se deve principalmente pelo problema da não existência do botão de voltar para tela anterior nas mensagens de erro, que foi corrigido.

Mas de uma forma geral, todos consideraram que as mensagens estão adequadas para as ações desempenhadas.

\section{CONSIDERAÇÕES FINAIS}

Com o avanço dos recursos tecnológicos, o número de publicações disponíveis na $W e b$ vem aumentado a cada dia. As BDs desempenham um papel importante na preservação de documentos, sendo considerada uma forma eficiente de armazenamento de informações e tem, por seu principal objetivo, auxiliar na recuperação de informação de forma rápida e objetiva.

Com a realização deste trabalho, foi possível verificar que uma $\mathrm{BD}$ é realmente uma forma eficiente de armazenamento e recuperação de trabalhos monográficos. Analisando os experimentos, foi constatado que, através da BDCUni, conseguiu-se documentar e registrar os trabalhos corretamente, facilitando a pesquisa e a recuperação das informações pesquisadas, e atendendo, de maneira satisfatória, as pretensões desejadas.

Vale salientar que a BDCUni consiste em um protótipo inicial e que manutenções já foram realizadas. Por exemplo, um serviço de autoarquivamento foi criado e melhorias no sentido de utilização da biblioteca foram implementadas. Como trabalho futuro, existe a necessidade da integração da BDCUni com outras bibliotecas por meio da utilização do padrão OAI.

\section{REFERÊNCIAS}

[1] DC. Dublin Core Metadata. "Dublin Core Web Site.", (2000). Disponível em: $<$ http://dublincore.org/documents/2005/08/15/us ageguide/>. Citado em 24 set, 2008.

[2] GALINDO, Marcos; PEREIRA, Marcos S.; LIMA, Cleiton M. V. Bibliotecas digitais e metadados: uma abordagem integradora. In: SIMPÓSIO INTERNACIONAL DE BIBLIOTECAS DIGITAIS, 2., 2004, Campinas, SP. Anais eletrônicos... Campinas, SP: UNICAMP, 2004. Disponível em: $<$ http://libdigi.unicamp.br/document/?view $=828$ 3_>. Citado em 27 set, 2008.

[3] GARCIA, Patrícia de Andrade Bueno. Provedores de dados de baixo custo: publicação digital ao alcance de todos. 2003. $128 \mathrm{f}$. Dissertação (Mestrado em Informática) Faculdade de Universidade Federal do Paraná, Curitiba, 2003. 
[4] GARCIA, Patrícia de Andrade Bueno. $O$ protocolo OAI-PMH para interoperabilidade em Bibliotecas Digitais. In: I CONGRESSO DE TECNOLOGIAS PARA GESTÃO DE DADOS E METADADOS DO CONE SUL, 2003, Ponta Grossa. I Congresso de Tecnologias para Gestão de Dados e Metadados do Cone Sul. 2003. v. 0, p. 0-0.

[5] MODESTO, Fernando. Metatados. São Paulo, 2005. Disponível em: $<$ http://www.eca.usp.br/prof/fmodesto/textos/liv rometadados.pdf>. Citado em 11 out, 2008.
[6] SHIMUZU, Heitor. O Fim de botões, fios $e$ baterias. Revista Época, Ciência e Tecnologia. São Paulo, n. 62, jul. 1999.

Disponível em: <http://epoca.globo.com/edic/19990726/ciencia 2.htm>. Citado em 11 out, 2008.

[7] SOUZA, Marcia Izabel Fugisawa \& VENDRUSCULO Laurimar Gonçalves \& MELO Geane Cristina. Metadados para a descrição de recursos de informação eletrônica: utilização do padrão dublin core. Ciência da Informação, v. 29, n. 1, p. 93-102, abr. 2000. 